\title{
Effect of Refractory Elements (X: Mo, W, Re) on the Microstructure Evolution of Fe-8Cr-0.1C-X Martensitic Steels during Tempering*1
}

\author{
Tomonori Kunieda $^{1, * 2}$, Yoshinori Murata ${ }^{1}$, Masahiko Morinaga ${ }^{1}$ and Toshiyuki Koyama ${ }^{2}$ \\ ${ }^{1}$ Department of Materials science and Engineering Graduate School of Engineering, Nagoya University, Nagoya 464-8603, Japan \\ ${ }^{2}$ National Institute for Materials Science, Tsukuba 305-0047, Japan
}

\begin{abstract}
It is well known that the refractory elements $(\mathrm{Mo}, \mathrm{W}, \mathrm{Re})$ play an important role in increasing the creep strength of heat resistant ferritic steels. However, the long-term creep strength of the ferritic steels depends on a number of factors, e.g., phase stability of the martensite, the diffusivity of alloying elements, the coarsening rate of precipitates in the steels, etc. Therefore, it is important for the future alloy design to make it clear the main factor influenced by the refractory elements. The purpose of this study is to examine the effect of the refractory elements only on the phase stability of martensite itself. For this purpose, the microstructure evolution was investigated using quaternary martensitic steels: Fe-Cr$\mathrm{C}-\mathrm{X}$ (X: Mo, W, Re). It was found that the microstructure evolution was retarded by the Re addition, since Re worked to increase the phase of the martensite and also to suppress the carbide $\left(\mathrm{M}_{23} \mathrm{C}_{6}\right)$ agglomeration during tempering. On the other hand, it was suggested that W could suppress the recovery of defects such as dislocations in the martensite phase.
\end{abstract}

(Received November 6, 2003; Accepted January 13, 2004)

Keywords: microstructure evolution, recovery, refractory element, heat-resistant steel, ferritic steel

\section{Introduction}

It is well known that the refractory elements $(\mathrm{Mo}, \mathrm{W}, \mathrm{Re})$ play an important role in increasing the creep strength of heat resistant high $\mathrm{Cr}$ ferritic steels. ${ }^{1-6)}$ In fact, these steels developed recently contain a relatively large amount of the refractory elements. ${ }^{7,8)}$ The microstructure of such a steel becomes quite complicated, i.e., it is composed of the martensite phase containing $\mathrm{M}_{23} \mathrm{C}_{6}$ carbide and $\mathrm{MX}$ carbonitrides together with intermetallic compounds such as the Laves phase. On the other hand, it has been reported that the long-term creep strength at $923 \mathrm{~K}$ becomes smaller than the value extrapolated from a short-term creep test. ${ }^{9)}$ It is believed that the decrease of the long-term creep strength is caused by the inhomogeneous microstructure evolution during creep. ${ }^{10)}$ This microstructure evolution depends on the sort of refractory elements. For example, Re is an element to retard the drastic decrease of the long-term creep strength but $\mathrm{W}$ is not. ${ }^{11)}$

The long-term creep strength depends on a variety of factors, e.g., the stability of the martensite phase, the diffusivity of alloying elements, the coalescence rate of precipitates in the steels, etc. But it is not clear which factor is affected mainly by the addition of refractory elements. It is important for material design to make it clear the main factor influenced by the refractory elements. The purpose of this study is to examine the alloying effect of refractory elements (Mo, W, Re) on the phase stability of the martensite. For this purpose, the microstructure evolution was investigated using quaternary martensitic steels: Fe-Cr-C-X (X: Mo, W, Re).

\footnotetext{
${ }^{* 1}$ This Paper was Presented at the Autumn Meeting of the Japan Institute of Metals, held in Hokkaido, on October 13, 2003

${ }^{* 2}$ Graduate Student, Nagoya University
}

Table 1 Chemical compositions of steels in this study, (mass\%).

\begin{tabular}{lcccccc}
\hline \multicolumn{1}{c}{ Steel } & C & Cr & Mo & W & Re & Fe \\
\hline Fe-Cr-C & 0.10 & 8.06 & - & - & - & Bal. \\
Fe-Cr-C-Mo & 0.10 & 8.07 & 0.52 & - & - & Bal. \\
Fe-Cr-C-W & 0.10 & 8.16 & - & 1.03 & - & Bal. \\
Fe-Cr-C-Re & 0.10 & 8.14 & - & - & 0.95 & Bal. \\
\hline
\end{tabular}

\section{Experimental Procedure}

\subsection{Steel preparation}

Four kinds of steels, i.e., one $\mathrm{Fe}-8 \mathrm{Cr}-\mathrm{C}$ ternary steel and three $\mathrm{Fe}-8 \mathrm{Cr}-0.1 \mathrm{C}-\mathrm{M}$ (M: $0.5 \mathrm{Mo}, 1.0 \mathrm{~W}, 1.0 \mathrm{Re})(\mathrm{mass} \%)$ quaternary steels were used in this study. The amount of the refractory elements was set to be low so as to suppress the formation of intermetallic compounds such as the Laves phase. ${ }^{12)}$ The chemical compositions of these steels are listed in Table 1. The ingots of these steels were prepared by vacuum induction melting and they were processed by hotforging in a conventional way. In order to control the grain size, these steels were normalized at $1373 \mathrm{~K}$ for $5 \mathrm{~h}$, followed by the tempering at $993 \mathrm{~K}$ for $20 \mathrm{~h}$. Subsequently, each steel was cut into a plate with the size of $10 \times 5 \times 5 \mathrm{~mm}$. The plate was austenitized at $1323 \mathrm{~K}$ for $5 \mathrm{~h}$ followed by quenching into water and immediately a sub-zero treatment was carried out using liquid nitrogen. After this quenching treatment, each plate was tempered at $873 \mathrm{~K}$ for $0.5 \mathrm{~h}, 1 \mathrm{~h}, 2 \mathrm{~h}, 4 \mathrm{~h}, 8 \mathrm{~h}$ and $16 \mathrm{~h}$.

\subsection{Vickers hardness test}

Each tempered specimen was mechanically polished with emery papers down to \#2000. After this polishing, Vickers hardness was measured using a load of $98 \mathrm{~N}$. The indentation size marked by using this load was about $200 \mu \mathrm{m}$ in diameter, which was much layer then the size of martensite laths and blocks. 


\subsection{Microstructure observation}

For the microstructure observation, each specimen was polished mechanically with emery papers down to \#2000 followed by the buff polishing with $\mathrm{Al}_{2} \mathrm{O}_{3}$ powders down to $0.3 \mu \mathrm{m}$. Subsequently, it was etched electrolytically using a $10 \mathrm{~mol} \%$-perchloric acid-acetic acid solution. After the etching, the microstructures in the specimens were observed with a scanning electron microscope (SEM) at an accelerated voltage of $20 \mathrm{kV}$. In order to confirm the martensite structure, optical microscopic observation was also carried out with the quenched specimens prepared in a conventional way.

\section{Results}

It was confirmed by optical microscopy that every experimental steel after the quenching treatment exhibited only the martensite phase without the retained austenite phase. Figure 1 shows the change in normalized Vickers hardness of the steels during tempering at $873 \mathrm{~K}$. The vertical scale of this figure is $\left(H_{\mathrm{i}}-H_{\infty}\right) /\left(H_{\mathrm{as}}-H_{\infty}\right)$. This is a suitable parameter in order to compare the degree of microstructure evolution among the experimental steels. Here, $H_{\mathrm{as}}$ is the hardness of the as-quenched specimen, namely, it is $395 \mathrm{Hv}$ for the ternary steel, $400 \mathrm{Hv}$ for the Mo doped steel, $403 \mathrm{Hv}$ for the $\mathrm{W}$ doped steel, and $438 \mathrm{Hv}$ for the Re doped steel. $H_{\infty}$ is the hardness of ferritic phase, i.e., $110 \mathrm{Hv}$, which was measured using the ferrite phase obtained from the ternary steel tempered at $1053 \mathrm{~K}$ for $168 \mathrm{~h} . H_{\mathrm{i}}$ is hardness of the specimen measured at each tempering time at
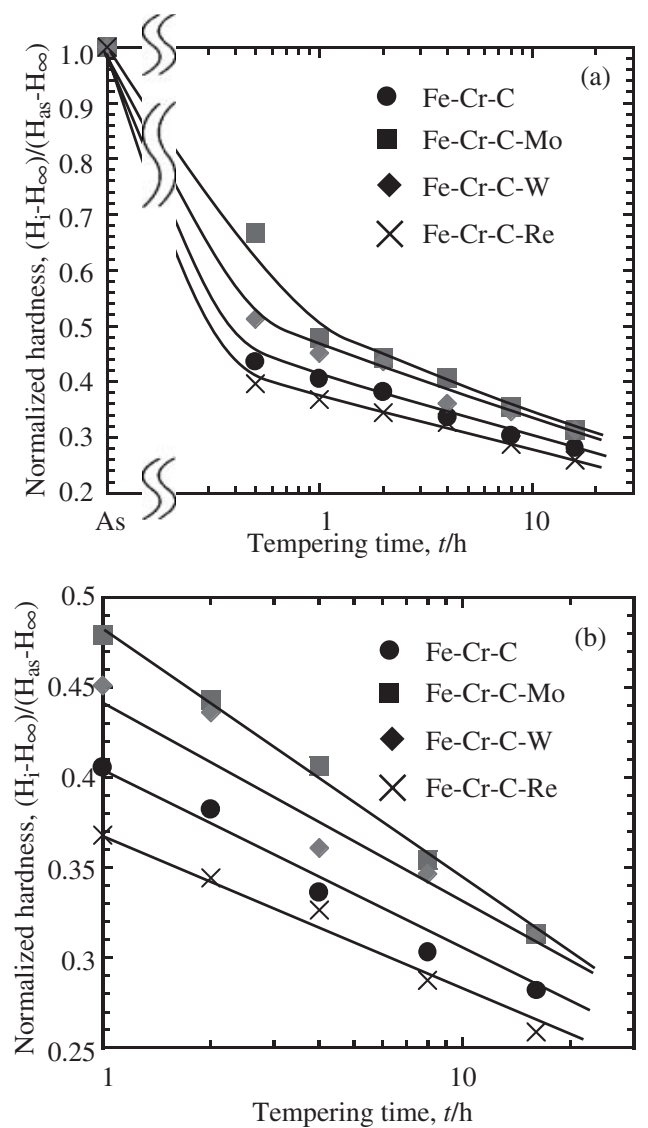

Fig. 1 Change in the normalized hardness with tempering time at $873 \mathrm{~K}$. (b) is an enlarged figure of the part after $1 \mathrm{~h}$ tempering in figure (a).
$873 \mathrm{~K}$. It was found from Fig. 1(a) that the hardness change by $1 \mathrm{~h}$ of the tempering was largest in the Re doped steel and smallest in the Mo doped steel. However, in view of the effect of the refractory elements on the long-term creep strength, it should be focused on the hardness change for a more prolonged tempering time. Thus the hardness change during tempering from $1 \mathrm{~h}$ to $16 \mathrm{~h}$ is shown in an enlarged scale in Fig. 1(b). From this figure, it is found that the largest decreasing rate during tempering from $1 \mathrm{~h}$ to $16 \mathrm{~h}$ is observed in the Mo doped steel. This result implies that the rate of microstructure evolution after $1 \mathrm{~h}$ tempering is the largest in the Mo doped steel among the experimental steels. However, microstructure evolution involves not only the recovery of the martensite structure but also the precipitation of the carbides, and hence it is necessary to investigate both the martensite recovery and the carbide precipitation.

Here, the martensite phase in the experimental steels consisted of the lath, block and packet substructures. Of these substructures, it is considered that Vickers hardness measured in this study depends mainly on the change in the block size, because the block boundaries have large difference in the crystallographic orientations from each other compared to the lath boundaries. Furthermore, any changes in both the lath and packet sizes are related directly to the change in the block substructure. In this study, therefore, the block substructure was employed as a measure of the microstructure evolution in the steels. Figure 2 shows the typical SEM microstructures taken from the specimens tempered at $873 \mathrm{~K}$ for $1 \mathrm{~h}$ ((a) and (b)) and for $8 \mathrm{~h}$ ((b) and (d)). The size of the martensite block in every steel increased with tempering time. Also, large carbides were observed in the SEM microstructure after tempering for $8 \mathrm{~h}$ as shown in Fig. 2(d). In the experimental steels, only $\mathrm{M}_{23} \mathrm{C}_{6}$ carbide was identified as the precipitate by X-ray diffraction using the extracted residues. This result is consistent with the expectation from the steel compositions, as mentioned in section 2.1. The amount of the carbide was very small in the ternary steel even after tempering for $8 \mathrm{~h}$ as shown in Fig. 2(c).

In order to study the microstructure in a more quantitative way, the average width of the martensite block as well as both the average size and the amount of the carbide were evaluated by an image analyzing method using SEM images. Figure 3 shows the change in the martensite block width with tempering time at $873 \mathrm{~K}$. In every steel, the growth rate of the block width did not increase linearly with tempering time, but slowed down after tempering for about $8 \mathrm{~h}$ in the quaternary steels. As shown in Fig. 3, the tendency of decreasing the growth rate is obvious in $\mathrm{Fe}-\mathrm{Cr}-\mathrm{C}-\mathrm{Mo}$ and $\mathrm{Fe}-\mathrm{Cr}-\mathrm{C}-\mathrm{Re}$ steels. On the other hand, the block width of Fe-Cr-C-W steel tempered for $16 \mathrm{~h}$ was largest among the three quaternary steels.

Figure 4 shows changes in the area fraction of $\mathrm{M}_{23} \mathrm{C}_{6}$ carbide with tempering time at $873 \mathrm{~K}$. The amount of the carbide increased with tempering time and the increase rate was conspicuous in the quaternary steels containing the refractory elements. This fact indicates that these refractory elements worked to promote the carbide precipitation, resulting in lowering of the $\mathrm{Cr}$ content in the martensite matrix phase. On the basis of the area fraction and the number of the carbide, the average size of the carbide was evaluated. 

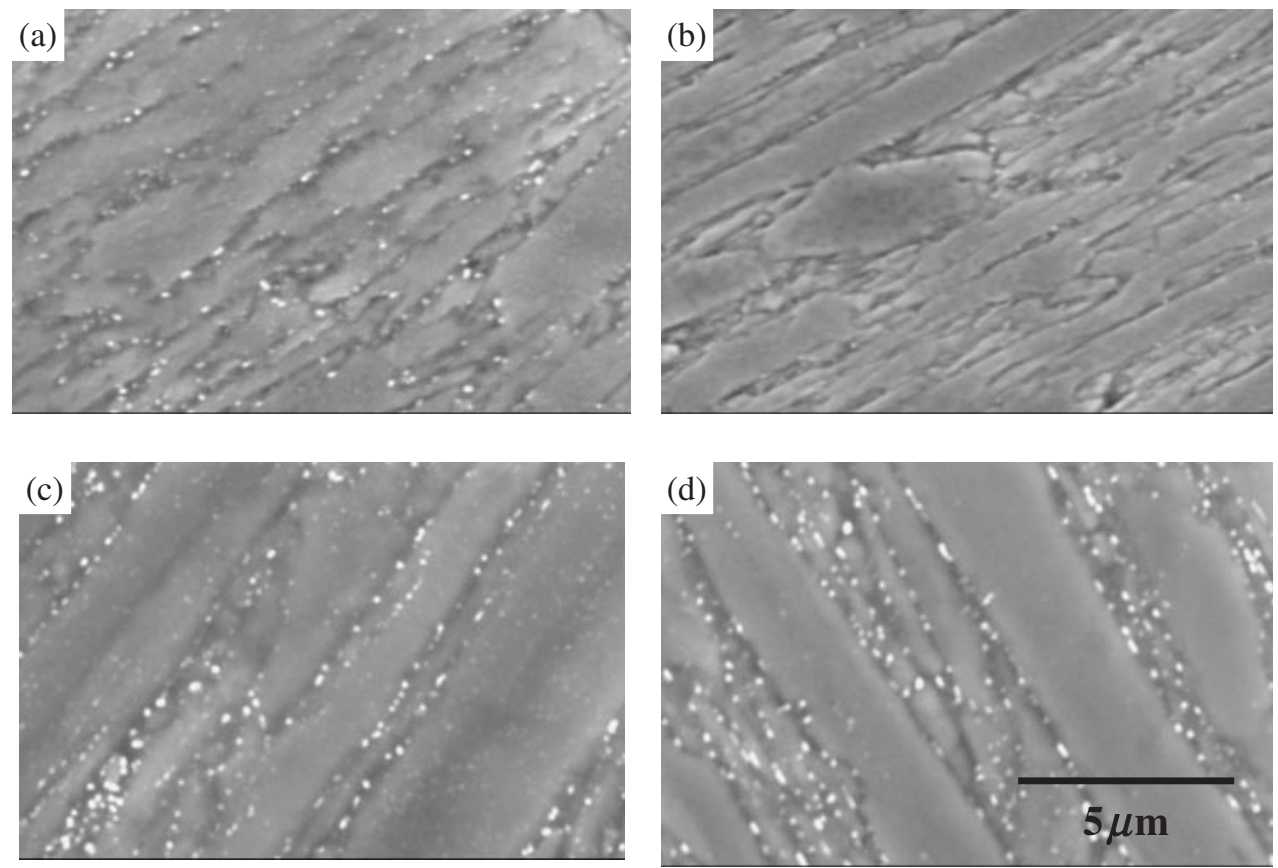

Fig. 2 SEM microstructures of, base steel, (a) and (c), and theRe-doped steel, (b) and (d). (a) and (b) are taken from the specimens tempered at $873 \mathrm{~K}$ for $1 \mathrm{~h}$, and (c) and (d) are taken from the specimens tempered at $873 \mathrm{~K}$ for $8 \mathrm{~h}$.

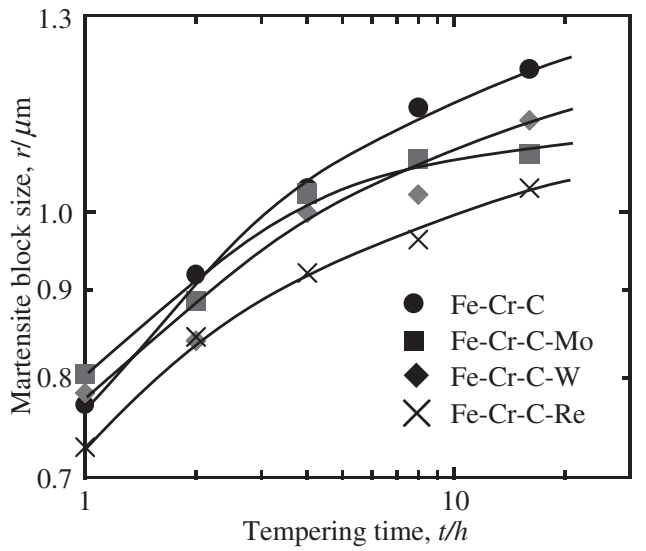

Fig. 3 Change in the martensite-block size with tempering time at $873 \mathrm{~K}$.

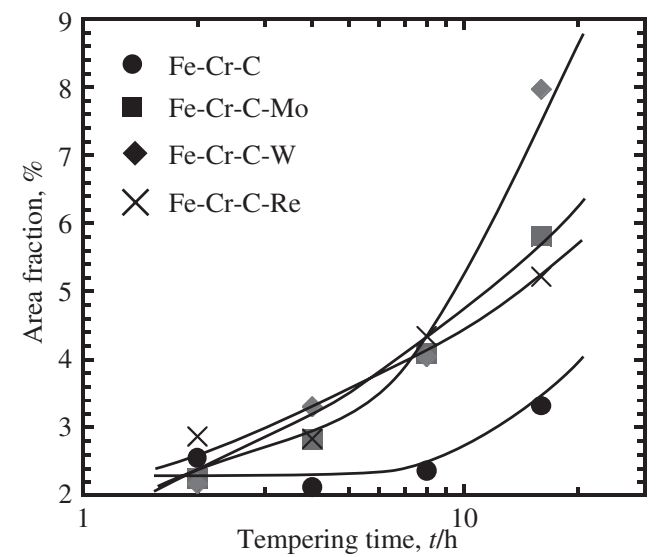

Fig. 4 Change in the amount of $\mathrm{M}_{23} \mathrm{C}_{6}$ carbide with tempering time at $873 \mathrm{~K}$.

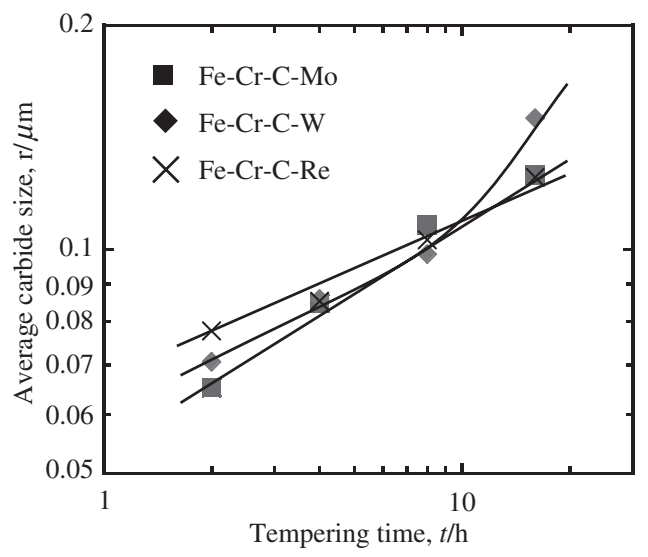

Fig. 5 Change in average size of $\mathrm{M}_{23} \mathrm{C}_{6}$ carbide with tempering time at $873 \mathrm{~K}$.

The average size is plotted as a function of tempering time, as shown in Fig. 5. Although any large differences in the average size were not observed among the quaternary steels, a rapid growth of the average size is found in $\mathrm{Fe}-\mathrm{Cr}-\mathrm{C}-\mathrm{W}$ steel tempered for $16 \mathrm{~h}$ at $873 \mathrm{~K}$. On the other hand, the Re doped steel exhibited the slowest growth rate among the quaternary steels.

\section{Discussion}

The size of the Vickers indentation observed in this study was large enough to cover a number of martensite blocks within the indentation, and hence the result shown in Fig. 1 reflected the microstructure changes: the strain within the martensite, the sizes of the martensite block and the carbide. As shown in Fig. 1(a), the normalized hardness of the steels tempered less than $1 \mathrm{~h}$ is high in the order $\mathrm{Mo}>\mathrm{W}>\mathrm{Re}$ 
containing steel. However, when the tempering time exceeded over $1 \mathrm{~h}$, the Mo-doped steel showed a steepest decrease in the hardness (Fig. 1(b)). This result implies that the microstructure change is retarded by the Mo addition in the initial stage but accelerated in the later stage of tempering over lh. This is consistent with our previous result ${ }^{13)}$ obtained from solid-solution binary iron-alloys: Fe-0.5 mol\%M (M: Mo, W, Re). The result showed that the Mo-doped iron exhibited the highest intra-grain hardness in the initial stage of annealing, but showed a rapid decrease in the hardness during subsequent annealing. As a result, the hardness inside the grain changed in the order of Re- $>\mathrm{W}->$ Mo-doped iron after annealing at $973 \mathrm{~K}$ for $8 \mathrm{~h}$. From this result, it is obvious that Mo is not so effective in holding the strain inside the grain of iron as W and Re. This Mo effect is probably similar to the case in the martensite phase of Fe-Cr-C-Mo steel.

The alloying effect of refractory elements (Mo, W, Re) on the microstructure evolution of the martensite phase in high $\mathrm{Cr}$ ferritic steels could be summarized as follows: (i) The recovery of strain inside the martensite phase was suppressed by the addition of the refractory elements and the degree of the effectiveness is in the order; $\mathrm{Re}>\mathrm{W}>\mathrm{Mo}$; (ii) The coalescence rate of the martensite block became slow in the presence of those refractory elements. The effect changed in the order; Re $>$ Mo $>$ W; (iii) The carbide coalescence was suppressed by alloying the refractory elements and its effect changed in the order; $\mathrm{Re} \approx \mathrm{Mo}>\mathrm{W}$. As a result, it is suggested that $\operatorname{Re}$ is most effective element to retard the microstructue evolution of the martensite phase.

\section{Conclusion}

In order to examine the effect of the refractory elements (Mo, W, Re) on the stability of the martensite phase during tempering at $873 \mathrm{~K}$, the microstructure evolution was investigated using martensitic quaternary steels: Fe-Cr-C-X (X: $\mathrm{Mo}, \mathrm{W}, \mathrm{Re}$ ). The results are summarized as follows;

Among the three quaternary steels, the growth rate of both the martensite block and $\mathrm{M}_{23} \mathrm{C}_{6}$ carbide was slowest in the Re containing steel. It is suggested that Re is more effective to making martensite structure stable even after a long time tempering than Mo or W.

\section{Acknowledgements}

This work was supported in part by the Grant-in-Aid for Scientific Research of Japan Society for the Promotion of Science (JSJP), Japan. The authors would like to thank Dr. T. Azuma and Mr. K. Miki of the Japan Steel Works Ltd., for providing the experimental steels.

\section{REFERENCES}

1) T. Fujita: Tetsu-to-hagane 76 (1990) 1053-1059.

2) H. Naoi, M. Ogami, Y. Hasegawa, H. Mimura and T. Fujita: Advanced Heat Resistant Steels for Power Plant Generation, eds. R. Viswanathan and J. Nutting, (Institute of Materials, London, 1999) 257-269.

3) K. Hidaka, Y. Fukui, S. Nakamura, R. Kaneko, Y. Tanaka and T. Fufita: Advanced Heat Resistant Steels for Power Plant Generation, eds. R. Viswanathan and J. Nutting, (Institute of Materials, London, 1999) 418-429.

4) Y. Murata, M. Morinaga, R. Hashizume, K. Takami, T. Azuma, Y. Tanaka and T. Ishiguro: Mater. Sci. Eng. A 282 (2000) 251-261.

5) Y. Murata, K. Takami, M. Kamiya, M. Morinaga, R. Hashizume, K. Miki, T. Azuma and T. Ishiguro: Tetu-to-Hagane 88 (2002) 214-221.

6) Y. Murata, K. Kawamura, M. Kamiya, M. Morinaga, R. Hashizume, K. Miki, T. Azuma and T. Ishiguro: ISIJ Int. 42 (2002) 1591-1593.

7) M. Masuyama: Tetsu-to-hagane 80 (1994) 587-592.

8) M. Sato, Y. Hasegawa, T. Muraki and K. Maruyama: J. Japan Inst. Metals 64 (2000) 371-374.

9) R. W. Vanstone: Microstructural Stability of Creep Resistant Alloys for High Temperature Plant Applications, ed. by A. Strang et al., (The University Press, Cambridge, 1997) 457-470.

10) H. Kushima, K. Kimura and F. Abe: Tetu-to-Hagane 85 (1999) 841.

11) F. Masuyama and N. Komai: Materials for Advanced Power Engineering 1998 (1998) pp. 269-276.

12) Y. Murata, T. Koyama, M. Morinaga and T. Miyazaki: ISIJ Int. 42 (2002) 1423-1429.

13) T. Kunieda, Y. Murata and M. Morinaga: to be published. 